\title{
Fundamental Research on the Administrative Discretion Standard
}

\author{
Yang Yang \\ School of Politic Science and Public Management, Southwest University, Chongqing, China. \\ Email: yangkent78@qq.com
}

Received June $2^{\text {nd }}, 2012$; revised July $8^{\text {th }}, 2012$; accepted July $18^{\text {th }}, 2012$

\begin{abstract}
This paper describes a system for the analysis of the administrative discretion standard. Now, it is a new phenomenon in the practice of administrative law enforcement. We shall first briefly introduce fuzzy sets and related concepts of the administrative discretion standard, and then, we try to introduce the intrinsic value of its legitimacy. At the same time, the research standard of interpretation, procedure and "requirements-effect" are discussed based on the analysis through its content. From the above discussion, the conclusion can be reached that it is the power's structure to deal with individuals and societies on the micro side.
\end{abstract}

Keywords: Administrative Discretion Standard; The Standard of Interpretation; The Standard of Procedure; The Standard of "Requirements-Effect"

\section{Introduction}

All areas in our living world must be monitored in the law-ruled society. In this situation, the administrative discretion standard as a means that controls administrative discretion emerges as the times require. It can be used to standardize the existing discretion power and compact the space of the existing discretion power as much as possible. However, what kind of value is its legitimacy based on? How should people grasp this legal phenomenon? This paper tries to find the answer through analyzing the text of the law enforcement.

Along with the State Council's distribution of the Comprehensive Advancement Legally Administration Implementation Summary in 2004 (Guo Fa [2004] No. 10 ), in order to implement "to win the people's confidence, governing for the people" concept, all executive authorities in the country have been setting a variety of the administrative discretion standards to seek the rationality and justice of the administrative discretion. The administrative discretion standard's practice is in full awing and is also increasing. Taking the public security system as an example, on January 30, 2010, Chongqing Municipal Public Security Bureau in China issued the work specification of Chongqing Municipal Public Security Bureau traffic patrol Police Service (Trial) for the newly established Police Traffic and Patrol that are responsible for the traffic management, the criminal law enforcement and the public security management. In fact, as early as in 2008, the Chongqing Municipal Public Security Bureau has printed and distributed a enforcement manual about the administrative discretion standardthe Disposal Specification of Public Security Organs for the Common Policing Alert. According to Administration Punishment Law, Beijing Municipal Public Security Bureau introduced the Specified Standards of Administration Punishment Law (Trial) by Beijing Municipal Public Security Bureau that combined with the characteristics of Beijing. Compared with Administration Punishment Law, the noise disturbance is subdivided into four action modes in the Specified Standards (Trial): firstly, he or she was informed and still not timely corrected, if the parking alarm has rung for a long time in area. Secondly, in hotels and other premises for operation, the noise of air conditioner and cooker hoods' outdoor unit is so loud that influences other people rest. Thirdly, affecting neighbors rest when entertainment in own house. Finally, interfering with any other rest when decorating a room during the break, Guangzhou City Public Security Bureau also issued the Guangzhou City Public Security Bureau for Guidelines of the Public Security Cases. The most typical example is the Administrative Discretion Standard System for the Public Security Penalty that was firstly introduced and broke personal case, relationship case and monetary case by Jinhua City Public Security Bureau in Zhejiang Province in 2003. According to it, 9120 cases and 25,658 penalty objects are dealt with, among which nobody refuses to ac- 
cept the punishment measures instituted for reconsideration and litigation [1].

In foreign countries, by explaining the concept of uncertainty in the law and setting elements-effect within the law, the social and administrative management's phenomenon is often seen that appeared in the form of rules, regulations, directives, standards, guidelines, memos, letters, notices, meeting minutes, the civil service manuals and a variety of training materials, etc. [2]. In France, the administrative discretion standard is known as the "indicator system". It refers to the executive authorities who have the discretion power set a standard in advance for themselves and their subordinate organs, as a guidance for the exercise of the discretion power, but still they have power to decide whether to apply the standard according to the specific circumstances of each case, it is designed to enable the universality and particularity of the administrative processing dialectically combined [3]. In Germany, the interpretation standard and discretion standard in the administrative rules are also in the form of method of interpretation and provisions for the way is stereotyped for the executive authorities on law interpretation. It is intended to restrain the discretion to ensure the unified application of the law [4]. In Japan, South Korea and Taiwan region of China, the "Administrative Procedure Act" is also provided for the discretion standard and its publication mechanism.

What is the administrative discretion standard? In view of the form, it is to standardize the detailed standards of law enforcement in the administrative discretion's enforcement. It takes the general normative documents as the carrier, and is a procedural, common and relatively uniform primary standard rather than the personalized, experiential or even random decision of law enforcement officers. From the content, it is as a medium or bridge for communication between abstract law and specific facts, and is closer to the "secondary legislation", "suborbinate legislation", "administrative legislation” whose purpose is to implement the law. Its range of effectiveness may only be involved in a microcosmic administrative area, and only be defined within a certain administrative region and a certain administrative department [5]. It is not difficult to summarize that the administrative discretion standard refers to which based on the legislative intention and discretionary authorization, under the guidance of certain objective value, that the executive authorities as subject did not provide the complete standard that required in dealing with the specific administrative cases in the laws and regulations of the social and administrative management, it is the administrative case judgment standard mainly presented in form of the normative documents and others, combined with law enforcement experience.

The next question is what a certain objective value is?

\section{The Value Direction: Order, Justice and Efficiency}

Firstly, the need of objective value in the functional significance. The standard itself is a tool; people can achieve a certain objective value through the tools. Value is the category that related to the subject's purpose, will or needs. Like science is a double-edged sword, the standard will deviate from its purpose if without value guidance. Secondly, the need of objective value in the standard significance. There is the rampant selfishness and consensus disintegration of the diverse social backgrounds. The perfection of the objective value often becomes a mutually acceptable proposal by interests of the parties. Do the value of the perfection of purpose still sought necessarily? Based on a wide range of value considerations, the discretion standard formulation authority eventually formed provisions that might have been deviated from the objective value which to show the "common good". Even so, the discretion standard formulation authority must put the objective value as the guidelines, looking back, thus, to sincerely seek the consensus of all parties of interest. In practice, the administrative organs at all levels across the country have introduced a variety of the discretion standards and refined the laws and regulations for the social management and public administration in order to resolve the social conflicts and innovate the social management and public administration. The phenomenon is existed generally that "proper awareness", "lack of science", "doing the local protection in the name of the standard", "lack of supervisory mechanism", "bending the law for the benefit of relatives and friends", "regional differences and chaos" and so on. [6] The emergence of various problems in local administrative discretion standard is the lack of the objective value as the guidelines and as contrast. What are the objectives of to show the human ideal of "common good"? They should be order, justice and efficiency. The reason that the three values is the objective value of administrative discretion standard, on the one hand, is that they are the most basic needs of the rules for people, On the other hand, is that the primary purpose of setting a rule by people is in order to achieve these three values.

Firstly, the administrative discretion standards have to meet people's need for order. First of all, order is the most basic needs of human beings. It is characterized by category among a series of things including order, stability, continuity and other states of relationship in space. It is a certain degree of consistency, continuity and coherence that exists in the natural and social processes is a fixed form in man's mode of production and life style. People can not share orderly the survival and life together without order. The administrative discretion standard as a rule of governance was written administrative 
normative documents of the text form and other forms to confirm and maintain the mode of production and lifestyle in the field of administrative law enforcement, and to ensure that the parties concerned in public administration can harmoniously coexist. It is undesirable for experience in applying Austin's ideas- “the existence of administrative discretion standard is one thing, its evaluation of its pros and cons is another matter". And even some parties concerned in the social management and public administration still do not have proper awareness and care for the necessity, importance and urgency of the administrative discretion power [6]. For another, the discretion standard has no order value's guidance will inevitably lead to execute the law without order. In this situation, the parties concerned in public administration, neither the parties concerned nor opposite person for administration are unable to make a definitive arrangements and then to be trapped in the respective state of danger. American jurisprudent Bodenheimer thinks that the order is a certain degree of consistency, continuity and coherence that exists in the natural and social processes. The administrative discretion standard that has order will bring a series of performance of social life, including the relationship stability, the processing continuity, the rules of behavior and property and psychological security of the parties concerned in the social management and public administration during the period of executing the law.

Secondly, the administrative discretion standard must meet people's need for justice. First of all, there is no human rights if without justice, the human is not different from animals. "Justice should not only be achieved, but also should be achieved in the way to be seen.” The statute law was written that the justice is considered as any behaviors for government law and regulations. Those who advocate the good of the community think that the justice is limited to useful action for it. Those who advocate natural law think that it is the ultimate foundation for justice. The discretion standard that embodied as the spirit of the rule of administrative law is to control the power in form; in essence, it is to realize individual justice. For another, the pursuit of justice is a constant need for human. The administrative discretion as an effective tool of administrative law enforcement is a sharp double-edged sword. It will become the hardest things to achieve individual justice if we correctly adopted it. It also will be the injury and murder weapon if we incorrectly adopted it "In which the government have both of the rule of law and the rule of man, the part of rule of man is like a fatal cancer and tend to stifle that part of the rule of law. Perhaps, 90 percent of the injustice in our legal system is from the discretion, but only 10 percent is from the rules [7]." So the administrative discretion should need to be restricted by the standard, it is for re- stricting the law enforcement personnel's personality, experiences and randomness to achieve the justice of individual case. Its original intention and effect will be bound to nothing and it will lead to a series of dissimilation problems in practice, if the law enforcement within the discretion standard is not under the guidance of justice value.

Thirdly, the administrative discretion standard must meet people's needs for efficiency. First of all, it requires the efficient administrative law enforcement in the modern economic life. Efficiency refers to the most effective use of social resources to satisfy people's wishes and needs. You can reach the most beneficial social results that based on the optimal allocation of resources when the unnecessary transaction costs and social costs are minimized if you choose the appropriate administrative rules. Secondly, people have the need for efficiently participating in the governance process of administrative law enforcement. In the context of democracy, it is the only choice that realizing the order and justice in the process of the administrative enforcement, consulting with the public and letting the public freely to participate in the formulation and implementation of the administrative discretion standard. But to let the citizens take part in the administrative discretion standard, which way is both democratic and efficient? How did we frame the administrative discretion standard that can reduce enforcement's hate and improve the efficiency of law enforcement? Dramatic changes in policy and the environment, it is asked to take a more sophisticated and more effective response in the field of administrative law enforcement. Because of the limited resources, the negotiation must be efficient and beneficial; otherwise the public and law enforcement authorities all will get tired of the endless consulations. Letting public participate in the formulation of the administrative discretion standard is a good policy that meets the tide of the modern democratization, while improving the public administrative efficiency. Efficiency is an important virtue in modern society, it is difficult to be regarded as an ideal and perfect society without efficiency. At the lack of efficiency as the objective value for introducing the administrative discretion standard, there will be happened in practice that "the staffs' behavior of administrative law enforcement has not been effectively regulated and controlled, such as: some have a serious privilege idea, lack of awareness of service and inefficient, some abuse of power and even abuse the law and practice favoritism during law enforcement [5].” It will cost the social resources, but with less enforcement effect.

Another problem is, although having the value direction, this subject is only defined within a certain administrative region and a certain administrative departments, its range of effectiveness may be only involved into the discretion standard of a microcosmic administrative area. 
What kind of appearance should we face the public and efficiently achieve the rules' governance of discretion?

\section{Rule Deduction: The Standard for Interpretation, Procedures, "Requirements-Effect"}

Which standards control can we truly need to achieve the governance of the administrative discretion in practice? On one hand, we can try to locate something by following up a clue for rule deduction by adopting the concept of administrative discretion standard as a starting point, the value as directions. On the other hand, from the practice of administrative law enforcement, the formation of discretion is mainly based on the following reasons: First is that it will result in the concept's ambiguity, due to the hard core of the legal concept in the text of laws and regulations may be large or small and fuzzy boundaries. At the same time, if it is combined with understanding differences of that are based on experience that will provide very big space for discretion power. Second is that the "requirements-effect" including procedures provisions, permission or punishment is provided for laws and regulations, and even the administrative departments also introduced the corresponding regulations to refined. In the actual enforcement, it is highly likely not to solve a case in the field of the microcosmic administrative enforcement, this in turn leave ample administrative discretion to the executive authorities. Therefore, by controlling the unnecessary discretion and reducing space of administrative discretion, to achieve a balance between rules and discretion, and eventually achieve "case justice", it is necessary to set the Standard for interpretation, procedures, "requirements-effect" (such as permission or punishment etc.) [8].

From the text of the relevant standard in practice, we can see the reply about control tool management for Beijing Public Security Bureau by Ministry of Public Security as follows.

Ceramic knives have the features of high hardness, high abrasion resistance and sharp edge, its technical properties have been met or exceeded the performance of some metal knives, ceramic knives should be managed as control knives that conform with the regulations of "the standard for controlled knives", such as knives' type, blade's length and knifepoint's angle [9].

This reply is the interpretation' standard for controlled knives in Security Administration Punishment Law 32. The Disposal Specification of Public Security Organs for the Common Policing Alert was introduced by Chongqing Municipal Public Security Bureau to improve the police's comprehensive ability in law and set the specific standard for law enforcement. The procedure of "the disposal for animal attacks" require as follow in the specification:

1) Animal owner should be ordered to keep a close watch on his animals when animals are attacking people; 2) The polices should take effective measures to stop the attack behavior if the owner is not present, no owner or laissez-faire by owner; 3) To inform victims themselves to the hospital when less injured and to take to take immediate measures to stop bleeding and notify 120 if it was injured severely; 4) He or she should be ordered to send the victim to medical and health institutions for treatment when the duty is clear for animal owners. To inform the parties to apply to the people's court or people's mediation organizations if the animal owner refuses; 5) Paying attention to the collection of fixed evidence, the investigation of the on-site insider access, preliminary judgment of the case properties; 6 ) Solving it according to the relevant procedures if criminal or administrative cases are under the jurisdiction of the public security organs; 7) Filling in and storing the alarming record, dealing with it according to relevant regulations if alarming results need to set a legal instrument... [10].

As mentioned above, this is the standard of programmed decision that directed according to Administration Punishment Law of the People's Republic of China, the Police Law of the People's Republic of China and Interim Measures of kennel management in Chongqing. Business bureau in Huiji district of Zhengzhou City formulates the corresponding standard for "requirementseffect according to the Provisions of Articles 15, 20, 33, 34 of the regulation of Rules of the Pig Slaughtering Management, seeing in the table below:

One, slaughtering pig without permission and in the fixed-location

1) the performance situation for minor illegal behavior

2) the performance situation for slight illegal behavior

3) the performance situation for general illegal behavior
Because the farmer family celebrates wedding ceremonies and funerals, they privately slaughter the live pig after purchasing it, but do not sale the pig product.

Since the farmers raise pig, they privately slaughter it after fattening pig, and have the sale behavior for it.

Slaughter personnel buy pig to slaughter without fixed-location, and take it as a means of operating profit.
The standard for fine: warning, registration violations and no fines.

The standard for fine: to impose on him a fine of not more than one times his illegal earnings.

The standard for fine: to impose on him a fine of not less than one time and not more than two times his illegal earnings. 


\section{Continued}

\begin{tabular}{|c|c|c|}
\hline $\begin{array}{l}\text { 4) the performance situation for } \\
\text { serious illegal behavior }\end{array}$ & $\begin{array}{l}\text { a. Slaughter personnel buy pig to slaughter without } \\
\text { fixed-location and take it as a means of operating } \\
\text { profit and the amount of illegal earnings is larger. } \\
\text { b. Slaughter personnel privately slaughter pig without } \\
\text { fixed-location. It caused harmful consequences } \\
\text { or social impact. } \\
\text { c. Slaughter personnel privately slaughter pig without } \\
\text { fixed-location and refused to stop the illegal behavior. }\end{array}$ & $\begin{array}{l}\text { The standard for fine: to impose on him a fine } \\
\text { of not less than two times and not more than three } \\
\text { times his illegal earnings. }\end{array}$ \\
\hline
\end{tabular}

\section{Conclusion}

In a word, it becomes obvious that the problem of the administrative discretion standard meet the requirement of the times, whatever it existed in advance in foreign or it is emerging in our native country, whatever researching it from the field of political science, public administration, administrative jurisprudence and sociology. Firstly, the administrative discretion standard is as a standard and rules for administrative enforcement power, it is as far as possible for the executive authorities that reasonably execute law, and it is framed through the objective value direction and rule deduction. The main function of administrative discretion standard is for the interpretation, including the interpretation of the uncertain legal concepts, and explanation of procedures, requirements-effect. Secondly, the standard should also be accompanied by the obligation to make it well known, but also to set its update system of the authorization file. Usually, it is necessary to introduce the system that can flexibly apply the standard, rather than rigidly apply it under certain conditions. Thirdly, furthermore, the administrative discretion standard can also be regarded as a kind of specification and self supervision for the administrative power, the "discipline" punishing for power on the micro view, an applied technology for the defaulted social power that is based on the congenital unequal theory. In short, the administrative discretion standard is the power's structure to deal with individuals and societies on the micro side, but the law is applied to maintain the social structure on the macro side. Its symbolic significance is a sign of the reform of administrative law enforcement and government administrative acts for our country and is a sample of the fairness and efficiency of public administration.

\section{Acknowledgements}

The research is supported by Research Fund of South- western University (NO.SWU1209301) and Humanities and Social sciences Research Fund of Chongqing Municipal Education Commission (NO.RWSK-CQJY-201101).

\section{REFERENCES}

[1] Q.-J. Lou, "Dealing with Prostitution Separation in Jinhua City,” Guangming Daily, February 2004.

[2] L. Sossin and C. W. Smith, "Hard Choices and Soft Law: Ethical Codes, Policy Guidelines and the Role of Counts in Regulating Government," Alberta Law Review, Vol. 40, 2003, pp. 867-893.

[3] M.-Y. Wang, "French Administrative Law," China University of Political Science and Law Press Ltd., Beijing, 1988.

[4] H. Maurer (Germany) and Translated by W. Gao, "Administrative Law Introduction,” Law Press Ltd., Beijing, 2000.

[5] L.-Y. Yu, "Walking between Norms and Rigid-Thoughts about the Practice of Administrative Discretion Standard in Jinhua District,” 3rd Edition, Tsinghua Law Ltd., Taiwan, 2008.

[6] L. P. Liu, "Legal Daily: The Common Five Problems of All Kinds of Administrative Discretion Standard,” 2009. http://news.sohu.com/20091020/n267537618.shtml

[7] K. C. Davis and Translated by H.-H. Bi,” Discretion Justice,” Commercial Press Ltd., Beijing, 2009.

[8] T.-H. Wang, "The Problem about the Basic Theory of Discretion Standard,” Zhejiang Academic Journal, Hangzhou, 2006.

[9] C. Y. Xie, "The Reply of Ministry of Public Security: Problem about Ceramic Knives into the Controlled Knives' Management," 2010. http://www.gongan.ningbo.gov.cn/004/008/43182.html

[10] X. Zhang, "The Public Information Network of Chongqing Municipal People’s Government: The Disposal Specification of Public Security Organs for the Common Policing Alert," 2008.

http://www.cq.gov.cn/subject/xzzfgg/zfdt/121229.html. 